\title{
Seroprevalencia de la infección por dengue en un distrito del Chaco Paraguayo. Estudio poblacional
}

\author{
Yenny Pereira, Margarita Samudio, Andrea Ojeda y Águeda Cabello
}

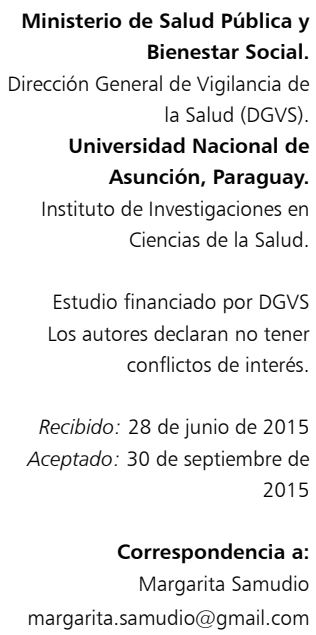

Ministerio de Salud Pública y Bienestar Social. Dirección General de Vigilancia de la Salud (DGVS) Universidad Nacional de Asunción, Paraguay. Instituto de Investigaciones en Ciencias de la Salud.

Estudio financiado por DGVS Los autores declaran no tener conflictos de interés.

Recibido: 28 de junio de 2015 Aceptado: 30 de septiembre de

Correspondencia a:

Margarita Samudio margarita.samudio@gmail.com

\section{Seroprevalence of dengue infection in a district of the Paraguayan Chaco. Population based study}

Background: Dengue is an infection of great global importance with different clinical presentations. Objective: To establish the seroprevalence of infection by the dengue virus in a district of the Paraguayan Chaco. Material and Methods: Cross-sectional study in 418 inhabitants of three villages in the district of Villa Hayes, Paraguay, using a probabilistic household sampling, a questionnaire and blood sampling. Antibodies were determined by the ELISA capture IgG anti dengue method and factors associated with seroprevalence were evaluated. Results: The overall seroprevalence for dengue virus infection was 24,2\% (CI95\%: 20,2\%-28,6\%); 34\% (n: 142) of respondents reported history of dengue in the previous 10 -year period. Of the 276 people $(66 \%)$ who reported no history of dengue infection, $37(13 \%)$ tested positive, which points out asymptomatic individuals. The main factors associated with infection were: males with significantly higher prevalence than women (31\%); to be over 60 years of age (44\%), be residents of Villa Hayes $(31,1 \%)$. No association with educational level or monthly income of the participants, nor housing condition, drinking water source or type of bathroom were observed. The larval infestation rate was $0,51 \%$. Conclusions: The relatively low seroprevalence of infection by the dengue virus is consistent with the small size of the district and highlights the potential risk of infection in future epidemics.

Key words: Seroprevalence, dengue, epidemiological study, Paraguay.

Palabras clave: Seroprevalencia, dengue, estudio epidemiológico, Paraguay.

\section{Introducción}

E 1 dengue es una arbovirosis de carácter endémicoepidémico, transmitida por mosquitos del género Aedes, principalmente por Aedes aegypti, y actualmente constituye una de las enfermedades más importantes en el mundo, en términos de morbilidad, mortalidad e impacto económico ${ }^{1,2}$.

Los virus del dengue pertenecen al género Flavivirus de la familia Flaviviridae. El complejo dengue lo constituyen cuatro serotipos serológicamente diferenciables (Dengue 1,2, 3 y 4) que comparten analogías estructurales y patogénicas. A pesar de que todos pueden producir potencialmente las formas graves de la enfermedad, los serotipos 2 y 3 han sido asociados con mayor frecuencia a casos más graves ${ }^{3}$.

El dengue puede tener diversas formas de presentación clínica, desde una fiebre indiferenciada o fiebre con cefalea, gran malestar general, dolores osteo-mio-articulares, con o sin exantema, leucopenia y algún tipo de sangrado, hasta formas graves con choque hipovolémico por extravasación de plasma, trombocitopenia moderada o intensa y grandes hemorragias en el aparato digestivo y otras localizaciones ${ }^{3}$.

La inmunidad que se genera por la infección debida a cada serotipo es duradera y manifestada por la presencia de anticuerpos neutralizantes homotípicos. No existe inmunidad cruzada entre serotipos, excepto durante las primeras semanas o meses después de la infección ${ }^{4}$. Cuando una persona tiene anticuerpos neutralizantes contra uno de los virus del dengue y es infectada por otro serotipo, se produce una amplificación dependiente de anticuerpos que se traduce en una elevada replicación viral y aumento de la viremia, lo cual condiciona y favorece el desarrollo de la forma grave de la enfermedad ${ }^{5}$.

El dengue se confirma durante la fase aguda mediante la detección de los virus en suero o sangre, tres días después del inicio de los síntomas, o por los anticuerpos específicos en el suero obtenido durante la fase de convalecencia, a partir de siete días del inicio de la enfermedad ${ }^{6}$.

Durante la última década, se ha registrado un dramático incremento de la infección por dengue en países sudamericanos como Colombia, Ecuador, Paraguay, Perú, Venezuela y Brasi ${ }^{7-9}$. En Brasil se encuentra aproximadamente $70 \%$ de todos los casos en América ${ }^{8}$, y en Colombia se ha registrado el mayor número de casos graves en los últimos años ${ }^{10}$.

En el Paraguay, el dengue se ha convertido en un importante problema de salud pública en los últimos años. La primera epidemia de dengue se registró en el 
período 1988-1989 con la circulación de DEN-1 y con una notificación total de 41.990 casos en todo el país. En el año 2010, los casos confirmados alcanzaron a 13.766 , con circulación de los serotipos DEN-1, 2 y $3^{11}$. Entre los años 2011 y 2012 se confirmaron 42.264 casos, circulando en forma simultánea los serotipos DEN 1 y DEN 2 en el 2011, y DEN-2 y DEN-4 en el 2012. Entre diciembre de 2012 y julio de 2013, se confirmaron por laboratorio $12.014(10 \%)$ y $113.572(90 \%)$ por nexo epidemiológico ${ }^{13}$.

La magnitud e intensidad de las interacciones entre el ambiente, el agente causal, la población de hospederos susceptibles y el vector transmisor definen la transmisión del dengue en una comunidad, región o país ${ }^{14}$. Una epidemia de dengue genera un alto impacto socio-económico en la población, mientras el aumento de casos con la circulación de varios serotipos constituye un serio factor de riesgo para el país ${ }^{15}$.

En países latinoamericananos se han realizado varios estudios sero-epidemiológicos de la infección por virus del dengue ${ }^{16-19}$ con resultados dispares. En Paraguay se desconoce el estado de susceptibilidad hacia este virus por falta de estudios de seroprevalencias en la población.

Se eligió para el estudio el distrito de Villa Hayes ubicado en el Departamento de Presidente Hayes, Chaco Paraguayo, a $35 \mathrm{~km}$ de la capital del país. Este distrito posee extensas áreas urbanas y rurales y condiciones ecológicas propicias para la transmisión del dengue. En el año 2012, en la semana epidemiológica 52, el Departamento de Presidente Hayes notificó 109 casos; 85\% correspondía al Distrito de Villa Hayes, identificándose el serotipo DEN $1^{20}$. En la zona no hubo corte de transmisión por lo que se la considera endémica. Los resultados de este estudio podrán poner de manifiesto el grado de susceptibilidad de una ciudad de tamaño poblacional pequeño.

Este estudio se realizó para determinar la seroprevalencia actual de la infección por dengue en Paraguay, además de establecer posibles asociaciones de la infección con las características clínicas y epidemiológicas de los pacientes.

\section{Pacientes y Métodos}

\section{Tipo, área y período de estudio}

Estudio observacional, descriptivo, de corte transversal. Fue realizado entre febrero y marzo de 2014 en el Distrito de Villa Hayes, cuya población estimada es de 34.511 habitantes, distribuidos $69,3 \%$ en zona urbana y $30,7 \%$ en zona rural. El área urbana lo conforman las siguientes localidades: Villa Hayes, Remansito, María Medianera, Pozo Colorado, Chacoi, Palmasola, Nueva Mestre, Río Verde, y Montelindo. El área rural lo componen 10 dispensarios indígenas: La Herencia, Lolaico, Xamoc Kasek, Yakie Axa, Sawhoyamaxa, Puerto Colon, Quenkunque, Makalawaya, Espinillo y Nepoxen y seis
Unidades de Salud Familiar: Paí Roberto, Chacoi, Ciudad Nueva, San Jorge y Río Verde ${ }^{21}$.

\section{Población de estudio y tamaño de la muestra}

Fueron seleccionadas tres localidades: Chacoi, Remansito y Villa Hayes. La primera constituida por cuatro conglomerados y 34 manzanas, la segunda por nueve conglomerados y 167 manzanas y Villa Hayes por 21 conglomerados y 393 manzanas.

Para la estimación del tamaño de muestra se consideró una prevalencia esperada de dengue de $50 \%$, una precisión de $5 \%$, un nivel de confianza de $95 \%$, y pérdida estimada de $5 \%$ (pérdidas previstas resultantes de la negativa y la existencia de viviendas cerradas durante la visita). El cálculo final de los hogares a cubrir se estimó en 418 viviendas.

\section{Criterios de inclusión y exclusión}

Todas las personas sobre dos años de edad, residentes en las localidades de Chacoi, Remansito y Villa Hayes, que en el momento del estudio estaban presenten y aceptaron participar del estudio firmando un consentimiento informado, fueron consideradas para la selección. (Ver párrafo: Asuntos éticos).

Todas las manzanas de las tres localidades antes mencionadas fueron enumeradas y sorteadas utilizando el Programa Randomise, obteniéndose para Chacoi: 3 manzanas, Remansito: 13 manzanas y Villa Hayes: 26 manzanas.

En cada manzana se seleccionaron 10 viviendas, empezando siempre por la esquina noroeste, visitando en forma consecutiva todas las casas. En caso de que no se conseguía reclutar el número deseado de participantes en una manzana se pasaba a la manzana de enfrente, tomando como referencia la casa inicial.

En cada hogar seleccionado se elegía un individuo y se realizaba la siguiente secuencia: se enumeraba a todos los miembros del hogar que estaban presentes en el momento de la visita asignándole a la persona de mayor edad el número $1, \mathrm{y}$ así sucesivamente. Una vez enumerados, se procedía al sorteo para la selección de la persona. En caso de que en la vivienda residiera una sola persona esa/e fue la/el seleccionada/o.

\section{Reclutamiento de participantes y toma de muestras sanguíneas}

En el hogar seleccionado, después de la clasificación de un miembro del hogar, previo consentimiento informado, el entrevistador informaba al entrevistado sobre la metodología, los beneficios, posibles riesgos y de la oportunidad de realizar consultas, a fin de decidir su participación en el estudio. Después de firmar el consentimiento libre e informado, el (o la) participante respondía el cuestionario con información sobre: sexo, edad, nivel de educación, 
ingreso familiar, condiciones de la vivienda, y otros antecedentes patológicos o no, procedencia, antecedentes de infección por dengue (primario, secundario), número de veces que se enfermó, signos y síntomas, ocurrencia de infección previa por dengue.

A las personas que durante el estudio presentaron algún signo o síntoma de enfermedad infecciosa se les tomó muestra de sangre para viremia y se llenó un cuestionario adicional con la información detallada sobre la sintomatología, cuestionarios que fueron incluidos en la vigilancia de síndrome febril agudo.

Las variables analizadas fueron las características demográficas (edad, sexo, procedencia, nivel de educación, ingreso familiar), resultado serológico, características clínicas (sintomática o no), tiempo de evolución (días desde el inicio de síntomas hasta el día de la consulta), antecedentes de infección por dengue, año o período de la infección, número de veces que enfermó, síntomas (cefalea, dolor estomacal, prurito), tratamiento recibido, respuesta al tratamiento, enfermedad de base y características epidemiológicas (condiciones de la vivienda).

\section{Levantamiento de índices de infestación aédica}

Finalizada la encuesta, se procedió a hacer la inspección directa de los hogares, captura de larvas e instrucción para la destrucción de los criaderos identificados y la geo-referenciación de los mismos. En cada una de las viviendas seleccionadas se inspeccionó los depósitos para agua ubicados en áreas peri-domiciliarias y espacios domiciliarios. Se consideró positiva una vivienda a la presencia de $A$. aegypti si, por lo menos, se registró una forma inmadura de la especie en alguno de los depósitos.

El material entomológico (larvas-pupas) fue capturado con un gotero, tipo pipeta plástica, debidamente rotuladas, indicando fecha, cantidad de ejemplares, dirección de la vivienda, número de encuesta y nombre del recolector, para su posterior análisis en el laboratorio de entomología. Los depósitos de agua que contenían formas inmaduras del vector se manejaron directamente con los habitantes de la vivienda, eliminando su contenido con tierra seca (en el caso de llantas) o desocupándolos e indicando la importancia del lavado de los mismos (en el caso de albercas o lavaderos y canecas). Además, se realizó capacitación a los habitantes de la vivienda en la prevención y control del mosquito y la eliminación de criaderos.

\section{Toma de muestras biológicas}

De cada individuo seleccionado se colectó $5 \mathrm{ml}$ de sangre periférica total sin anticoagulante, por personal capacitado. Las muestras de sangre fueron codificadas e inmediatamente acondicionadas en cajas térmicas de Isopor ${ }^{\circledR}$ refrigeradas hasta el momento de su almacenamiento y posterior procesamiento en el laboratorio Central de Salud Pública.

\section{ELISA de captura de IgG anti dengue}

Fue utilizado el ensayo inmunoenzimático comercial IgG SD Dengue IgG Capture ELISA ${ }^{\circledR}$ (Standard Diagnostics, Inc), que consiste en un ELISA de captura para la detección de anticuerpos IgG contra el antígeno de virus dengue en suero humano. El kit contiene una microplaca con pocillos cubiertos con anticuerpos monoclonales de ratón anti IgG humana. Durante la primera incubación, los anticuerpos IgG anti dengue presentes en el suero humano, se pegan a los anticuerpos monoclonales anti IgG humana en los pocillos, y luego se pega a la mezcla el antígeno de dengue y anticuerpos monoclonales de ratón anti dengue conjugados con peroxidasa de rábano picante. Todo el material no pegado, es removido en los lavados después de cada incubación. La actividad enzimática residual encontrada en los pocillos es directamente proporcional a la cantidad de IgG anti dengue presente en suero humano, y evidenciado por la incubación final con sustrato TMB.

Las muestras de pacientes y los controles fueron diluidos 1/100 en el diluyente provisto por el kit; $100 \mu \mathrm{l}$ de esta dilución fue colocada en los pocillos e incubada a $37^{\circ} \mathrm{C}$ durante una hora. La placa fue lavada cinco veces con PBS-Tween $20 \%$. Fueron agregados $100 \mu \mathrm{lde}$ la mezcla de antígeno y conjugado a cada pocillo, y la placa fue incubada nuevamente a $37^{\circ} \mathrm{C}$ por una hora. Se repitió el mismo procedimiento de lavado. Luego fueron agregados $100 \mu \mathrm{l}$ del sustrato TMB a cada pocillo y la placa fue incubada a temperatura ambiente por $10 \mathrm{~min}$. Finalmente, se añadieron $100 \mu \mathrm{l}$ de solución de parada a cada pocillo. La absorbancia del color desarrollado fue leída en un lector de ELISA Biotek ELx 800 a una longitud de onda de $450 \mathrm{~nm}$ con un filtro de referencia de $620 \mathrm{~nm}$. Fueron consideradas positivas todas las muestras cuyas absorbancias resultaron superiores a la media de los controles negativos más 0,300 .

\section{Análisis estadísticos}

Los datos fueron introducidos en una hoja de cálculo de Microsoft Excel que luego fueron analizados en el programa Epi Info 7. Las variables cualitativas fueron expresadas en frecuencias y las cuantitativas en medidas de tendencia central y dispersión. La variable demográfica tuvo tres focos de análisis (edad, sexo, procedencia). La primera variable fue analizada hallando la media o la mediana de acuerdo a los datos encontrados, con los rangos respectivos y así comparar la gravedad del cuadro clínico en los diferentes grupos de edad. El sexo fue discriminado por grupo de edad, hallando las medidas de tendencia central y de dispersión. En la caracterización de los casos clínicos se analizaron siete variables: antecedentes patológicos, serotipo circulante, tiempo de evolución de la enfermedad, número de veces que enfermó, síntomas, tratamiento y respuesta al mismo, co-morbilidades (se analizaron las patologías). Se realizó porcentaje del 
número de veces que la persona enfermó, se realizó un cruce entre el tratamiento y la respuesta al mismo con las co-morbilidades o existentes, para ver si el tratamiento aplicado resultó adecuado o no.

\section{Asuntos éticos}

El trabajo fue aprobado por el Comité de Ética de la Universidad Nacional de Asunción (D.I. Núm. 17/2014 en fecha 13 de marzo de 2014). Se explicó al individuo que los datos obtenidos en el estudio con relación a su persona: "serán custodiados, guardando celosa garantía de discreción y confidencialidad sobre su identificación. Así mismo, la gratuidad de la participación, y que esta enfermedad es de importancia en Salud Pública, ya la misma podría presentar cuadros leves y graves que podrían inclusive llevar a la muerte, por lo tanto, este tipo de estudios ayudará a identificar y conocer si la enfermedad está presente en la comunidad y así poder proponer medidas de prevención y control, para evitar la ocurrencia de los casos".

En los casos de menores de edad, el consentimiento fue otorgado por escrito por su representante legal, tras haber recibido y comprendido la información mencionada. Si el/la participante no pudiera leer y firmar el formulario de consentimiento, se obtendrá de forma oral en presencia de un testigo. El paciente recibió una copia del consentimiento firmado y la otra copia fue conservada por el investigador.

\section{Resultados}

Fueron visitadas 601 viviendas, de las cuales 42 jefes de hogares $(7 \%)$ se negaron a participar del estudio y 141 viviendas estaban cerradas $(24 \%)$ en el momento de la visita. Finalmente, se incluyeron en el estudio 418 personas, 32 procedentes de la localidad de Chacoi, 132 de Remansito y 254 de Villa Hayes (Tabla 1).

\section{Características demográficas y ambientales (Tabla 2)}

El 66\% (n: 276) de los participantes era de sexo femenino. La mediana de edad fue de 49 años (rango: 4 a 92 años). El 49\% de los participantes tenía nivel primario de educación y $13 \%$ nivel terciario. En cuanto a su ocupación, $37 \%$ de la población encuestada era ama de casa. El ingreso de 221 (53\%) personas era menor del salario mínimo legal vigente. El 8\% de los encuestados reportó vivir solo y $128(31 \%)$ en condiciones de hacinamiento. En relación a las características de las viviendas, $87 \%$ de las viviendas tenía pared de ladrillo; $85 \%$ de los pobladores tenía acceso al servicio de agua corriente público, ESSAP. El 69\% de la población contaba con letrina moderna.
Tabla 1. Distribución de los encuestados en el estudio de seroprevalencia de dengue en el Distrito de Villa Hayes, febrero-marzo 2014 (n: 418)

\begin{tabular}{|llrr|}
\hline Localidad & Barrios & $\mathbf{n}$ & $\%$ \\
Villa Hayes & Pañete & 155 & 61 \\
n: 254 (61\%) & Golondrina & 66 & 26 \\
& San Juan & 12 & 4 \\
& Alonso & 7 & 3 \\
& Cuidad Nueva & 5 & 2 \\
& San Jorge & 5 & 2 \\
& Cerro & 2 & 1 \\
& San Roque & 2 & 1 \\
Remansito & Remansito & 36 & 27 \\
n:132 (31\%) & San Isidro & 24 & 18 \\
& San Vicente & 22 & 17 \\
& María Auxiliadora & 17 & 13 \\
& Centro & 12 & 9 \\
& Martir Luisa & 11 & 8 \\
Chacoi & San Jorge & 10 & 8 \\
n: 32 (8\%) & Barrio Central & 32 & 100 \\
\hline
\end{tabular}

\section{Características clínicas de la población estudiada}

Un total de 108 (26\%) personas reportaron padecer de hipertensión arterial; $34(8 \%)$ de diabetes mellitus; 9 (2\%) de cardiopatía y 267 (64\%) no reportaron patología de base. Refirieron no haber enfermado antes de dengue 267 personas (64\%); 142 (34\%) refirieron haber enfermado alguna vez en el período de 10 años anteriores, mientras que 9 personas $(2 \%)$ desconocían su condición en relación de haber enfermado de dengue. La mayoría reportó haberse enfermado entre los años 2012 y 2013; de ellos 109 (77\%) eran procedentes de Villa Hayes, en su mayoría del barrio Pañete 70 (64\%) y del barrio Golondrina 29 (26\%).

El síntoma más común reportado por las 142 personas que habían enfermado de dengue fue fiebre (81\%); 127 encuestados $(89 \%)$ recibieron asistencia médica, la mayoría $(63 \%)$ en hospitales públicos. Trece $(9 \%)$ no consultaron y refirieron que la cura fue espontánea; 35 (25\%) pacientes fueron hospitalizados y de ellos, en $66 \%$ la hospitalización duró más de 5 días (Tabla 3).

En relación al autoreporte de enfermar de dengue, se encontró estadísticamente $(\mathrm{p}<0,0001)$ mayor proporción de personas de Villa Hayes (43\%) que lo refirieron en comparación de Remansito (21\%) y Chacoi (16\%).

\section{Resultados serológicos}

La IgG anti dengue fue positiva en 101 personas, lo que representa una seroprevalencia para el dengue en el Distrito de Villa Hayes de 24,2\% (IC95\%: 20,2\%-28,6\%). Por lo tanto, el grado de susceptibilidad calculado para Villa Hayes es de 69\%, para Remansito $85 \%$ y para Chacoi 94\% (diferencias estadísticamente significativa). 
Tabla 2. Características generales de los participantes del estudio de seroprevalencia de dengue en el Distrito de Villa Hayes, febrero-marzo 2014 (n: 418)

$\begin{array}{lrr}\text { Características } & \text { Frecuencia } & \% \\ \text { Sexo } & & \\ \text { Femenino } & 276 & 66 \\ \text { Masculino } & 142 & 34 \\ \text { Edad (mediana, rango) (años) } & 49 & 4-92 \\ <10 & 6 & 1 \\ 10-19 & 42 & 10 \\ 20-40 & 185 & 44 \\ 41-60 & 110 & 27 \\ \geq 61 & 75 & 18\end{array}$

Nivel educativo

$\begin{array}{lrr}\text { Analfabeto } & 18 & 4 \\ \text { Primario completo } & 205 & 49 \\ \text { Secundario completo } & 142 & 34 \\ \text { Terciario/ universitario } & 53 & 13\end{array}$

Ocupación

$\begin{array}{lrr}\text { Ama de casa } & 155 & 37 \\ \text { Comerciante } & 71 & 18 \\ \text { Obrero } & 63 & 15 \\ \text { Estudiante } & 43 & 10 \\ \text { Profesional universitario } & 35 & 8 \\ \text { Funcionario público } & 31 & 7 \\ \text { Empleada doméstica } & 13 & 3 \\ \text { Desempleado } & 7 & 2\end{array}$

Ingreso mensual

$\begin{array}{lrr}\text { Menos del salario mínimo } & 221 & 53 \\ \text { Más del salario mínimo } & 116 & 28 \\ \text { No tiene ingreso } & 81 & 19 \\ \text { Vive solo } & 33 & 8 \\ \text { Hacinamiento* } & 128 & 31 \\ \text { Tipo de vivienda } & & \\ \text { Pared de ladrillo } & 363 & 86 \\ \text { Madera } & 52 & 12 \\ \text { Plástico/ barro } & 3 & 2\end{array}$

Servicio de agua para consumo

$\begin{array}{lrr}\text { Agua corriente ESSAP } & 356 & 85 \\ \text { Agua embotellada } & 47 & 11 \\ \text { Pozo } & 15 & 4\end{array}$

Tipo de baño

$\begin{array}{lrr}\text { Baño moderno } & 287 & 68 \\ \text { Letrina mejorada } & 16 & 4 \\ \text { Letrina común } & 115 & 28\end{array}$

*Hacinamiento: si la relación entre el número de personas que viven en la casa y el número de dormitorios con que cuenta la vivienda era superior a 3 .
Tabla 3. Características de la población que auto reportó dengue en el estudio de seroprevalencia de dengue en el Distrito de Villa Hayes, febrero-marzo 2014 (n: 142)

\section{Características}

n

$\%$

Año en que enfermó

$1998-2000$

2005-2006

2008-2009

2010-2011

2012-2013

2014

No recuerda

$\begin{array}{rr}4 & 3 \\ 3 & 2 \\ 3 & 2 \\ 14 & 10 \\ 114 & 80 \\ 1 & 1 \\ 3 & 2\end{array}$

Procedencia

Villa Hayes

Barrio Pañete

Barrio Golondrina

Barrio San Juan

Barrio Cerro, San Jorge, Villa Graciela, Ciudad Nueva

$109 \quad 77$

$70 \quad 64$

$29 \quad 26$

$6 \quad 6$

Remansito

Barrio Remansito

Barrio María Auxiliadora, San Vicente

Barrio Martir Luisa, San Isidro

Barrio San Jorge, El Progreso

Chacoi

Barrio Central

44

$28-20$

9232

828

$\begin{array}{ll}8 & 28\end{array}$

$5 \quad 18$

5

$5 \quad 100$

Síntomas reportados

Fiebre

Artralgias, mialgias

Cefalea, petequias

Recibió asistencia médica debido al dengue

$115 \quad 81$

Servicios donde recibió asistencia médica

Hospital público

IPS

Privado

No consultó

Farmacia

Hospitalizado

115
9

7

127

89

Tiempo de hospitalización (n: 35)

Menos de 5 días

Más de 5 días

$\begin{array}{rr}90 & 63 \\ 23 & 16 \\ 14 & 10 \\ 13 & 9 \\ 2 & 2 \\ 35 & 25 \\ 12 & 34 \\ 23 & 66\end{array}$

Tabla 4. Auto-reporte de dengue y confirmación por el laboratorio, según localidad en el estudio de seroprevalencia de dengue en el Distrito de Villa Hayes, febrero-marzo 2014

\begin{tabular}{|c|c|c|c|c|c|}
\hline \multicolumn{6}{|c|}{ Localidad } \\
\hline & $\begin{array}{c}\text { Villa Hayes } \\
\text { (n: } 254)\end{array}$ & $\begin{array}{c}\text { Remansito } \\
\text { (n: 132) }\end{array}$ & $\begin{array}{l}\text { Chacoi } \\
\text { (n: 32) }\end{array}$ & $\begin{array}{c}\text { Total } \\
\text { (n: 418) }\end{array}$ & Valor $p$ \\
\hline \multicolumn{6}{|l|}{ Auto-reporte de dengue } \\
\hline Refirió enfermar & $109(43 \%)$ & $28(21 \%)$ & $5(16 \%)$ & $142(34)$ & $<0,0001$ \\
\hline No enfermó & $139(55 \%)$ & $103(78 \%)$ & $25(78 \%)$ & $267(64)$ & \\
\hline Desconoce & $6(2 \%)$ & $1(1 \%)$ & $2(6 \%)$ & $9(2)$ & \\
\hline Resultado de laboratorio & & & & & 0,0001 \\
\hline $\lg G$ positivo & $79(31 \%)$ & $20(15 \%)$ & $2(6 \%)$ & $101(24,2)$ & \\
\hline IgG negativo & $175(69 \%)$ & $112(85 \%)$ & $30(94 \%)$ & $317(75,8)$ & \\
\hline
\end{tabular}


De las 276 personas que refirieron no haber enfermado de dengue, 37 (13\%) dieron positivos en la muestra serológica, lo que se interpreta como que estas personas fueron asintomáticos (Tabla 4).

De los 142 encuestados que refirieron enfermar de dengue, a $64(45 \%)$ se le confirmó esa condición por el método de ELISA, para los 78 (55\%) restantes la prueba fue negativa (Tabla 5).

\section{Factores asociados a la serología positiva (Tabla 6)}

El sexo masculino presentó significativamente mayor seropositividad que el femenino. La prevalencia por grupo etario fue aumentando con la edad, siendo los adultos sobre 60 años quienes presentaron la mayor prevalencia $(44 \%)$. En cuanto a la procedencia, se vio una mayor prevalencia en los residentes en la localidad de Villa Hayes $(31,1 \%)$; los casos positivos se vieron distribuidos en diferentes barrios de la zona. Fueron más afectadas las personas desempleadas (42,9\%), seguida de los obreros (39\%). Las personas que reportaron vivir solos reportaron con mayor frecuencia $(42,4 \%)$ haber padecido de dengue anteriormente. No se observó asociación con el nivel educativo, el ingreso mensual, el tipo de vivienda, fuente de agua potable ni tipo de baño.

\section{Búsqueda de larvas en los hogares (Tabla 7)}

De 194 casas investigadas, se encontró una casa con criaderos indicando un índice de infestación larvaria de $0,51 \%$. Los recipientes investigados fueron 573 , recipientes positivos 2 y el índice de recipientes fue $0,34 \%$.

\section{Discusión}

En los últimos 10 años, el dengue ha sido un importante problema de salud pública en el Paraguay; su incidencia y distribución geográfica se ha expandido continuamente con la aparición de casos graves. Entre diciembre de 2012 y julio de 2013, se confirmaron por laboratorio más de 100.000 casos.

La seroprevalencia para el dengue en el Distrito de Villa Hayes fue de $24,2 \%$, con diferencias significativas entre las localidades estudiadas. La zona de estudio más afectada por el virus del dengue fue la localidad de Villa Hayes en los Barrios Pañete y Golondrina. El grado de susceptibilidad para adquirir la infección en el momento del estudio era, por lo tanto, alta en las tres localidades, $69 \%$ para Villa Hayes, $85 \%$ para Remansito y $94 \%$ para Chacoi.

Comparando la seroprevalencia encontrada en nuestro estudio con otros realizados en Latinoamérica encontramos grandes diferencias de acuerdo a factores como el tamaño de la población y antecedentes de epidemias, entre otros $^{16-19}$. Vasconcelos y cols. ${ }^{16}$, refirieron prevalencias de infección por virus de dengue entre 25 y $56 \%$, en base
Tabla 5. Comparación entre auto-reporte de dengue y confirmación por laboratorio del estudio de seroprevalencia del dengue, febrero-marzo, 2014

\begin{tabular}{|lccc|}
\hline Referencia del encuestado & IgG positivo & Negativo & Total \\
Enfermó de dengue & $64(45 \%)$ & $78(55 \%)$ & 142 \\
No enfermó & $36(13 \%)$ & $231(87 \%)$ & 267 \\
Desconoce & $1(11 \%)$ & $8(89 \%)$ & 9 \\
Total & 101 & 317 & \\
\hline
\end{tabular}

Tabla 6. Factores asociados a la serología positiva para dengue en la población del estudio de seroprevalencia de dengue en el Distrito de Villa Hayes, febrero-marzo 2014

$\begin{array}{lrrr}\text { Variables } & \text { Total } & \text { Seropositivo } & \text { Valor de } \\ \begin{array}{l}\text { Sexo } \\ \quad \text { Masculino }\end{array} & 142 & 45(31,7 \%) & 0,009 \\ \quad \text { Femenino } & 276 & 56(20,3 \%) & \\ \begin{array}{l}\text { Grupo etario (años) } \\ \quad 10\end{array} & 6 & 1(16,7 \%) & <0,001 \\ \quad 10-19 & 42 & 5(11,9 \%) & \\ 20-40 & 185 & 24(13 \%) & \\ 41-60 & 110 & 38(34,5 \%) & \\ \geq 60 & 71 & 33(44 \%) & \end{array}$

\section{Nivel educativo}

Analfabeto

Primario

$6(33,3 \%)$

0,3664

Secundario

$\begin{array}{rr}18 & 6(33,3 \%) \\ 205 & 56(27,3 \%) \\ 142 & 29(20,4 \% \\ 53 & 10(41,2 \%)\end{array}$

Terciario/universitario

$10(41,2 \%)$

Ocupación

Ama de cas

Comerciante

$28(18,1 \%)$

Obrero/a

$21(29,5 \%)$

Estudiante

Profesional universitario

Funcionario público

Empleada doméstica

Desempleado

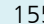

71

$25(39,7 \%)$

$4 \quad(9,3 \%)$

$11(31,4 \%)$

$7(22,6 \%)$

$3(15,4 \%)$

$3(42,9 \%)$

Ingreso mensual

Superior al sueldo mínimo

$8(24,1 \%)$

Inferior al sueldo mínimo

No tiene ingresos

Tipo de vivienda Barro/plástico

Madera

Pared/ladrillo

Provisión de agua

Servicio público ESSAP

Embotellada

Pozo

Tipo de baño

Baño moderno

Letrina mejorada

Letrina común

Vive solo
Sí
No
33
$14(42,4 \%)$
$87(22,6 \%)$
385
0,0083

$56(25,3 \%)$

$17(21 \%)$

\section{0}

$6(11,5 \%)$

$95(26,2 \%)$

$83(23,3 \%)$

$13(27,7 \%)$

$5(33,3 \%)$

$75(26,1 \%)$

$5(31,3 \%)$

$21(18,3 \%)$

0,7362

0,0989

0,565

0,3319

$\begin{array}{rr}16 & 5(31,3 \%) \\ 115 & 21\end{array}$




\begin{tabular}{|c|c|c|c|c|c|c|}
\hline \multirow[b]{2}{*}{ Recipientes } & \multicolumn{2}{|c|}{ Villa Hayes } & \multicolumn{2}{|c|}{ Chacoi } & \multicolumn{2}{|c|}{ Remansito } \\
\hline & Existentes & Positivos & Existentes & Positivos & Existentes & Positivos \\
\hline \multicolumn{7}{|l|}{ Útiles } \\
\hline Tanques, cisternas & 8 & - & 1 & - & - & - \\
\hline Tambor & 29 & 2 & 16 & 2 & 50 & 2 \\
\hline Bebedero de animales & 110 & - & 30 & - & 142 & - \\
\hline Cántaros & 1 & - & - & - & - & - \\
\hline Aljibes, pozos & - & - & 2 & - & 2 & - \\
\hline Otros & 26 & - & 3 & - & 10 & - \\
\hline \multicolumn{7}{|l|}{ Inservibles } \\
\hline Neumáticos usados & 30 & - & 21 & 2 & 62 & 1 \\
\hline Aparatos domésticos descartados & 7 & - & - & - & - & - \\
\hline Cubetas descartadas & 6 & - & - & - & 2 & - \\
\hline Latas & 211 & - & 90 & 2 & 339 & - \\
\hline Botellas & 145 & - & 221 & - & 325 & - \\
\hline Otros & - & - & 1 & 1 & - & - \\
\hline Total & 573 & 2 & 385 & 7 & 932 & 3 \\
\hline
\end{tabular}

a estudios realizados en ciudades pequeñas. La mayoría de estos estudios se realizaron después de las primeras epidemias detectadas ${ }^{16-19}$. Un estudio realizado en Salvador, Bahía, Brasil, ciudad de mayor tamaño, mostró una prevalencia más alta $(68,7 \%)$, pero, en el momento del estudio, ya habían transcurrido cuatro años de transmisión $^{22}$. En censos realizados en dos ciudades pequeñas del Estado de Bahía, después de las primeras epidemias detectadas, se encontraron prevalencias de 11,9 y $17,5 \%{ }^{23}$. En Campinas, Brasil, fue de $14,7 \% \%^{24}$ y en Santa Bárbara d'Oeste también en la región de Campinas con 145.266 habitantes, en 1995, después de la primera epidemia detectada, se observó una prevalencia muy baja $(0,6 \%)^{25}$. En la ciudad de Ribeirão Preto ${ }^{26}$, con una población de 430.312 habitantes, la prevalencia fue de 5,4\%. Otros estudios han encontrado prevalencias mayores, como aquel efectuado en una población del estado de Veracruz que encontró una seroprevalencia contra el virus del dengue de casi $80 \%{ }^{27}$, y otro en la población del estado de Yucatán, que reveló una seroprevalencia de anticuerpos inhibidores de la hemaglutinación (IH) de $72,5 \%{ }^{28}$. Por lo tanto, concluimos que la prevalencia encontrada en Villa Hayes $(24,2 \%)$ es consistente con las encontradas en ciudades de tamaños pequeños.

Gran porcentaje (66\%) de la población estudiada desconocía si alguna vez enfermó de dengue; sin embargo, los resultados de laboratorio en ellos dieron positivos en $13 \%$ de los casos, lo que pone de manifiesto la condición de asintomáticos con que cursaron la enfermedad. De los encuestados que refirieron haber enfermado de dengue, a $45 \%$ se le confirmó serológicamente, además a uno de los nueve que desconocía su condición. Esto evidencia que un importante porcentaje de la población presentó alguna enfermedad febril diferente al dengue.

Cerca de $90 \%$ de los entrevistados reconoce la fiebre como el principal síntoma de dengue, similar a lo evidenciado por García y cols., en el Municipio Sifontes de Tumeremo, Estado Bolívar ${ }^{29}$. Los siguientes síntomas reconocidos por las personas fueron artralgias y mialgias. El vómito y la diarrea más bien corresponden a eventos relacionados con el tracto gastrointestinal, mientras que la cefalea, mialgias y artralgias, más orientadores a dengue, fueron reconocidos por menos de $20 \%$ de los encuestados. En un estudio realizado por Guzmán y cols., en niños de 0-15 años, los síntomas más frecuentes fueron fiebre y mialgias $^{30}$.

La mayoría (89\%) de las personas que reportaron haber enfermado por dengue recibió asistencia médica, cifra similar a otros estudios ${ }^{31}$. Esta práctica es bastante alentadora porque da la oportunidad de tener un manejo adecuado del dengue y la correspondiente notificación del caso, seguimiento y orientación de medidas ambientales para evitar la transmisión a otras personas.

En la literatura científica revisada, se encontró mayor afectación por dengue en el sexo femenino, tanto para adquirir la infección como para complicarse y agravarse ${ }^{32}$. González Mata y cols., encontraron una distribución similar (sexo femenino 67,5\%), atribuyéndola a estilos de vida, como mayor permanencia de la mujer en los hogares ${ }^{33}$, dado que $A$. aegypti es generalmente criado en el hogar. Sin embargo, en el presente estudio se observó mayor prevalencia $(31,7 \%)$ en hombres, en forma concordante con lo encontrado con Vielma y Díaz Santos $(66,7 \%$ en el sexo masculino) $)^{34,35}$. 
La distribución de la enfermedad, según la edad, varía de una zona geográfica a otra. En los países de sudeste asiático los niños constituyen la población más afectada, mientras en los países americanos todos los grupos de edad se afectan por igual ${ }^{36}$. En esta serie, la prevalencia por grupo etario mostró que fue aumentando con la edad, siendo los mayores de 60 años los que presentaron la mayor prevalencia (44\%). Mostorino y cols., reportaron una edad media de 31,0 años, con un predominio de los sujetos entre los 20 y 39 años $^{37}$; en otros estudios predominaron los grupos de 42 a 52 años ${ }^{35}$.

Uno de los factores de riesgo que se destaca en la literatura científica es el bajo nivel escolar, pues enfermedades como el dengue tienen mayor impacto en aquellas poblaciones de bajo recursos económicos y de mayor pobreza, donde existe mayor probabilidad de condiciones para la presencia de criaderos del vector. Además, este bajo nivel escolar coincide generalmente con el desconocimiento sobre la enfermedad, sus mecanismos de transmisión y la prevención. En nuestro estudio, el mayor número de encuestados tenía un nivel escolar primario completo (49\%) o secundario completo (34\%); sólo 4\% no tenía escolaridad. La prevalencia de la infección encontrada en todos los niveles fue similar.

A diferencia de otros estudios, con índices larvarios muy altos ${ }^{31,38}$, en nuestro estudio el índice de infestación larvaria fue de $0,5 \%$, considerado de bajo riesgo, por debajo del rango de $0,9 \%$ aceptado por la Organización Mundial de la Salud (OMS), Se considera de "riesgo" entre 1 y $4 \%$ de infestación hogareña, y por encima de este rango se habla de una situación de "alto riesgo". La mayoría de los criaderos se encontraron en los tambores, a diferencia de otros estudios donde se encontraron en los lavaderos domiciliarios ${ }^{39}$.

En el año 2012, en la semana epidemiológica 52, el Departamento de Presidente Hayes notificó 109 casos; 85\% correspondió al Distrito de Villa Hayes, donde se detectó un brote en el barrio Pañete. El serotipo identificado en ese distrito fue DEN 1. La seroprevalencia encontrada en este estudio permite inferir que 8.352 personas, en el Distrito de Villa Hayes, fueron infectadas por el virus del dengue. Considerando que en la epidemia de 2014, fueron notificados sólo 140 casos, el número de individuos con serología positiva para dengue es muchas veces mayor. Si consideramos los casos notificados en los años anteriores, en los cuales fue detectada transmisión, el número total de casos notificados fue de 252; el número estimado de seropositivos es muy superior al de los notificados. Analizando estudios sero-epidemiológicos realizados en otros países, se observan grandes variaciones en los valores encontrados.
En el Municipio de Prado, Bahía, Brasil, la relación fue ocho veces mayor de seropositivos que los casos de dengue notificados y, en el mismo estudio, en el Municipio de Ipupiara, Bahía, Brasil, ese valor fue 1,3 veces menor ${ }^{40}$. En el Municipio de Campinas con 137.906 habitantes el estudio de seroprevalencia detectó 25,8 veces más ${ }^{24}$.

El Distrito de Villa Hayes, pese a hallarse en una zona con las condiciones ecológicas más propicias para el desarrollo del mosquito vector, A. aegypti, y estar entre los límites de Región Central con mayor transmisión informada, puede considerarse una zona aún de baja transmisión. Considerando que el control del dengue no es puramente de epidemiólogos, se necesita de la intersectorialidad, aparte de eliminar criaderos del peridomicilio y practicar medidas de control y estimular la participación de la comunidad en actividades comunitarias, entre ellas las medidas de prevención y control del dengue.

\section{Resumen}

Introducción: El dengue es una infección de gran importancia mundial con diferentes formas clínicas de presentación. Objetivo: Establecer la seroprevalencia de infección por el virus del dengue en un distrito del Chaco paraguayo. Material y Métodos: Estudio transversal en 418 habitantes de tres localidades del Distrito de Villa Hayes, Paraguay, mediante un muestreo probabilístico por hogares, aplicación de cuestionario y toma de muestras sanguíneas. Se buscaron anticuerpos por el método ELISA de captura de IgG anti dengue y se evaluaron factores asociados a la seroprevalencia. Resultados: La seroprevalencia global para el virus del dengue fue 24,2\% (IC 95\%: 20,2\%-28,6\%); 34\% (n: 142) de los encuestados refirió haber enfermado alguna vez de dengue en el período de 10 años anteriores. De las 276 personas (66\%) que refirieron no haber enfermado de dengue, 37 (13\%) resultaron positivos en la prueba serológica, lo que destaca la condición de asintomáticos con que cursaron la enfermedad. Los principales factores vinculados con la infección fueron: sexo masculino (prevalencia: $31,7 \%$ ); ser mayor de 60 años (prevalencia: 44\%); residencia en la localidad de Villa Hayes (prevalencia: 31,1\%). No se observó asociación con el nivel educativo o ingreso mensual de los encuestados, tampoco con el tipo de vivienda, fuente de agua potable o tipo de baño. El índice de infestación larvaria fue $0,51 \%$. Conclusiones: La relativa baja seroprevalencia de la infección por el virus del dengue es consistente con el tamaño pequeño del distrito y demuestra el riesgo potencial de enfermar en futuras epidemias. 


\section{Referencias bibliográficas}

1.- Guzmán M G. Dengue, one of the great emerging health challenges of the 21 st Century. Expert Rev Vaccines 2004; 3 (5): 511-20.

2.- Wearing H J, Rohani P. Ecological and immunological determinants of dengue epidemics. Proc Natl Acad Sci USA 2006; 103 (31): 11802-7.

3.- Gubler D J. Dengue and dengue hemorrhagic fever. Clin. Microbiol. Rev 1998; 3: 480-96.

4.- Martínez E. Dengue y dengue hemorrágico. Buenos Aires: Ed. Univ. Quilmes, 1998.

5.- Halstead S B. Dengue hemorrhagic fever: two infections and antibody dependent enhancement, a brief history and personal memoir. Rev. Cubana Med. Trop 2002; 54 (3): 171-9.

6.- World Health Organization. Dengue haemorrhagic fever. Diagnosis, treatment, prevention and control. Geneva, 1997. p.1-84.

7.- Stephenson J R. The problem with dengue. Trans R Soc Trop Med Hyg 2005; 99: 643-6.

8.- Siqueira J B Jr, Martelli C M, Coelho G E, Simplicio A C, Hatch D L. Dengue and dengue hemorrhagic fever, Brazil, 1981-2002. Emerg Infect Dis 2005; 11: 48-53.

9.- Uzcategui N Y, Comach G, Camacho D, Salcedo M, Cabello de Quintana M, Jiménez M, et al. Molecular epidemiology of dengue virus type 3 in Venezuela. J Gen Virol 2003; 84 (Pt 6): 1569-75.

10.- Pan American Health Organization. Number of reported cases of dengue and dengue hemorrhagic fever (DHF). Region of the Americas (by country and subregion). Washington, DC, Panamerican Health Organization, 2009. (accedido el 3 de febrero de 2014). Disponible en: http://www.paho.org/hq/ index.php?option $=$ com_topics \&view $=$ rdmore \& cid=6290\&Itemid=40734 \&lang=en

11.- República del Paraguay. Ministerio de Salud Pública y Bienestar Social. Dirección General de Vigilancia de la Salud. Boletín Epidemiológico Anual de 2010. Edición Especial de cierre de 2010 (acedido el 3 de febrero de 2014). Disponible en: http:// vigisalud.gov.py/images/documentos/ boletines/2011.01.12\%20boletin $\% 20$ epidemiologico.pdf

12.- República del Paraguay. Ministerio de Salud Pública y Bienestar Social. Dirección General de Vigilancia de la Salud. Boletín Epidemiológico. Edición $\mathrm{N}^{\circ} 49$. Semana epidemiológica: 52, año 2011. (acedido el 3 de febrero de 2014). Disponible en: http:// vigisalud.gov.py/images/documentos/ boletines/2011.12.30\%20boletin $\% 20$ epidemiologico.pdf

13.- República del Paraguay. Ministerio de Salud Pública y Bienestar Social. Dirección General de Vigilancia de la Salud. Boletín
Epidemiológico. Edición $\mathrm{N}^{\mathrm{o}}$ 50. Semana epidemiológica: 52, año 2012. (accedido el 3 de febrero de 2014). Disponible en: http:/vigisalud.gov.py/images/documentos/ boletines/2012.12.28\%20boletin $\% 20$ epidemiologico.pdf

14.- Gómez H, Ramos B, Tapia R. El riesgo de transmisión del dengue: un espacio para la estratificación. Salud Publica Mex 1995; 37 Suppl: 88-97.

15.- La implementación del Dengue Net en las Américas [Informe]. Puerto Rico. OMS/ OPS/CDC. WHO/DC/CSR/GAR/2003.8. Washington: OMS /OPS/CDC;2003

16.- Vasconcelos P F C, Mota K, Straatmann A, Santos-Torres S, Travassos-da-Rosa APA, Tavares Neto J. Epidemia de dengue em Ipupiara e Prado, Bahia: inquérito soroepidemiológico. Rev Soc Bras Med Trop 2000; 33: 61-7.

17.- Figueiredo L T M, Cavalcante S M B, Simões M C. Encuesta serológica sobre el dengue entre escolares de Río de Janeiro, Brasil, 1986 e 1987. Bol Of Sanit Panam 1991; 111: 525-33.

18.- Vasconcelos P F C, Lima J W O, Raposo M L, Rodrigues S G, Travassos-da-Rosa J F S, Amorim S M C, et al. Inquérito soroepidemiológico na Ilha de São Luís durante epidemia de dengue no Maranhão. Rev Soc Bras Med Trop 1999; 32: 171-9.

19.- Vasconcelos P F C, Lima J W O, Travassosda-Rosa A P A, Timbó M J, Travassos-da-Rosa E S, Lima H R, et al. Epidemia de dengue em Fortaleza, Ceará: inquérito soro-epidemiológico aleatório. Rev. Saúde Pública 1998; 32: 447-54.

20.- República del Paraguay. Ministerio de Salud Pública y Bienestar Social. Dirección General de Vigilancia de la Salud. Boletín epidemiológico. Edición $\mathrm{N}^{\mathrm{o}}$ 51. Semana epidemiológica: 52, año 2012. (acedido el 2 de febrero de 2013). Disponible en: http:// vigisalud.gov.py/images/documentos/ boletines/2013.01.04\%20boletin $\% 20$ epidemiologico.pdf

21.- Atlas Censal del Paraguay. Pte. Hayes. Ubicación geográfica. (accedido el 2 de febrero de 2013). Recuperado de: http://www.dgeec. gov.py/Publicaciones/Biblioteca/Atlas $\% 20$ Censal\%20del\%20Paraguay/18\%20Atlas\%20 Pte.\%20Hayes\%20censo.pdf

22.- Teixeira M G, Barreto M L, Costa M C N, Ferreira L D A, Vasconcelos P. Dinâmica de circulação do vírus da dengue em uma área metropolitana do Brasil. Epidemiol Serv Saúde 2003; 12: 87-97.

23.- Figueiredo L T M, Travassos-da-Rosa A P A, Fiorillo A M. Níveis de anticorpos para arbovírus em indivíduos da região de Ribeirão Preto, SP (Brasil). Rev. Saúde Pública 1986; 20: 204-11.

24.- Lima V L C, Rangel O, Andrade V R, da Silveira N Y J, de Oliveira S S, Figueiredo L T M. Dengue: inquérito populacional para pesquisa de anticorpos e vigilância virológica no Municipio de Campinas, São Paulo, Brasil. Cad. Saúde Pública 2007; 23 (3): 669-80.

25.- Lima V L C, Figueiredo L T M, Correa Filho H R, Leite O F, Rangel O, Vido A A. Dengue: inquérito sorológico pósepidêmico em zona urbana do Estado de São Paulo (Brasil). Rev Saúde Pública 1999; 33 : 566-74.

26.- Figueiredo L T M, Owa M A, Carlucci R H, Fabero A L, Mello N V D, Capuano D M, et al. Encuesta serológica sobre el dengue em Ribeirão Preto, São Paulo, Brasil. Bol Of Sanit Panam 1995; 118: 499-509.

27.- Navarrete-Espinosa J. Prevalence of dengue and leptospira antibodies in the state of Veracruz, Mexico. Salud Pública Mex 2006; 48 (3): $220-8$.

28.- Lorono-Pino M A, Farfán-Ale J A, Rosado-Paredes E P, Arjona-Torres A I, Flores-Flores L F, Manzano-Cabrera L A, et al. Prevalencia de anticuerpos contra el virus dengue en Yucatán, México, 1985. Rev Latinoam Microbiol 1989; 31: 259-62.

29.- García A, Núñez P, Betí I, Bastidas W, Rosal N. 2005 Incidencia de dengue en el Municipio Autónomo Sifontes y su comportamiento clínico epidemiológico, por medio de casos confirmados serológicamente en el Hospital tipo I "Dr. José Gregorio Hernández” de Tumeremo, Estado Bolívar. Enero-noviembre de 2004. 2005. CAIBCO.

30.- Guzmán M A, Martínez S, Guzmán N, Mateo P, Koenig E. Seroprevalencia de anticuerpos contra el virus dengue en niños de 0-15 años. Arch Dom Pediatr 1994; 30 (2): 35-7.

31.- Cáceres-Manrique FM, Vesga-Gómez C, Perea-Florez X, Ruitort M, Yves Talbo. Conocimientos, actitudes y prácticas sobre dengue en dos barrios de Bucaramanga, Colombia. Rev Salud Pública 2009; 11 (1): 27-38.

32.- Arias J. El dengue en Cuba. Rev Panam Salud Pública 2002; 11 (4): 221-2.

33.- González Mata A J, Colina de Guevara L, Maitín M. Dengue hoy. Boletín Médico de Posgrado. 2002 abril-junio; 18 (2): 83-6.

34.- Vielma S, Muñoz M, Pérez-Lo Presti S, Téllez L, Quintero B, Mosqueda N, et al. Hallazgos clínicos y de laboratorio en pacientes con dengue. Revisión de criterios diagnósticos. Revista de la Facultad de Farmacia 2006; 48 (1): 2-5. Disponible en: http://www.saber.ula. ve/bitstream/123456789/23881/1/articulo2.pdf

35.- Díaz Santos E C, Borrego Díaz L R, González Saps K. Comportamiento del dengue en cooperantes internacionalistas cubanos del Municipio Bolívar en Venezuela. Años 20042007. Correo Científico Médico de Holguín. 
2008; 12 (3): 1-9. Disponible en: http://www. cocmed.sld.cu/no123/n123ori1.html

36.- Halstead S B. Dengue in the Americas and Southeast Asia: do they differ? Rev Panam Salud Pública 2006; 20 (6): 407-15.

37.- Mostorino R, Rosas A, Gutiérrez V, Anaya E, Cobos M, García M. Manifestaciones clínicas y distribución geográfica de los serotipos del dengue en el Perú-Año 2001. Rev Per Med Exp Salud Pública. 2002 octubre-diciembre; 19 (4): 171-80.

38.- Benítez-Leite S, Machi M L, Gilbert E, Rivarola $\mathrm{K}$. Conocimientos, actitudes y prácticas acerca del dengue en un barrio de Asunción. Rev Chil Pediatr 2002; 73: 64-72.

39.- Rodríguez H, De La Hoz F P. Dengue and dengue and vector behaviour in Cáqueza, Colombia, 2004. Rev Salud Pública (Bogotá) 2005; 7: 1-15.

40.- Figueiredo L T M, Simões M C, Cavalcante S M B. Enzime immunoassay for the detection of dengue IgG and IgM antibodies using mosquito cells as antigen. Trans R Soc Trop Med Hyg 1989; 83: 702-7. 